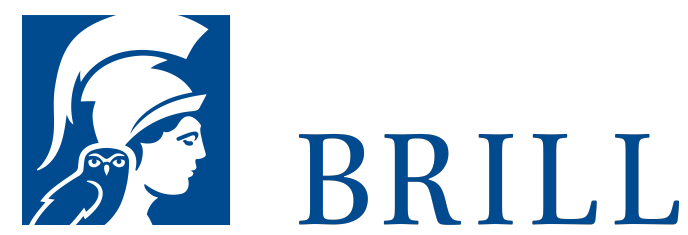

\title{
Quelle und Prinzip
}

Rhetorische Grundlagen, poetische Konzepte, philologische

Metaphorik, 1700-2000

\section{Author: Marcel Lepper}

Die Konjunktur von Ressourcenfragen in den Philologien gibt Anlass, einen Schritt zurückzutreten und nach der älteren Metapher zu fragen: nach der rhetorischen, poetischen und philologischen »Quelle «.

Etabliert sich die »Quelle« als Terminus im engeren Sinne tatsächlich erst in den verwissenschaftlichten Philologien des 19. Jahrhunderts? Wie stark überlagert der romantische und postromantische Leitdiskurs alternative Quellenverständnisse? Je genauer man hinsieht, desto deutlicher erweist sich die Quellenmetapher als hintergründig, vielschichtig, problematisch. Wo verflacht die Rede von der Quelle in der Metaphernvergessenheit der Hilfswissenschaften? Wo wird das Versprechen der Unerschöpflichkeit zur Zumutung und Bedrohung? An welcher Stelle kommt das Ressourcenverständnis als Gegenszenario ins Spiel?

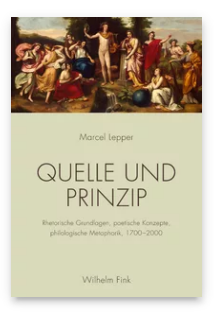

Published: 30

Apr 2024

\section{Subjects:}

German,

Literature and

Cultural Studies

Publisher: Brill |

Fink

E-Book (PDF)

ISBN: $978-3^{-}$

8467-6o28-4

Hardback

ISBN: 978-3-

7705-6о28-8 
Marcel Lepper lehrt Neuere Deutsche Literatur an der Universität Stuttgart und leitet das Forschungsreferat sowie die wissenschaftsgeschichtliche Arbeitsstelle im Deutschen Literaturarchiv Marbach. Forschungsaufenthalte führten ihn u.a. an die University of Kent, Canterbury (2013), ans Zentrum für Literatur- und Kulturforschung, Berlin (2016) und an die Princeton University (2016).

Please send your order to: Brockhaus/Commission Tel: +49(o)71 541327 9216 | E-Mail: brill@ $\underline{\text { brocom.de }}$

For questions please contact: Brill Deutschland GmbH Wollmarktstraße 115 | 33098 Paderborn | Germany Tel: +49 (o)5251 69975 o | E-Mail: sales@brill.com. 